\title{
Effect of human colostrum on interleukin-2 production and natural killer cell activity
}

\author{
Lea Sirota, Rachel Straussberg, Ida Notti, Hanna Bessler
}

\begin{abstract}
The effect of human colostrum on the production of interleukin-2 (IL-2) and on natural killer (NK) cell activity by peripheral blood mononuclear cells (PBMC) was investigated in $\mathbf{5 0}$ healthy women. At concentrations as low as $0.5 \%$, human colostrum stimulated IL-2 production; at a higher concentration (10\%), IL-2 secretion was inhibited. $A$ time and dose dependent inhibitory effect of colostrum on NK cytotoxicity was also observed. This inhibition could be reversed by the addition of human recombinant IL-2 (hrIL-2).

The stimulation of IL-2 production induced by human colostrum might compensate for its inhibitory effect on NK cell activity. These findings suggest an additional mechanism by which breast feeding may affect the neonatal immune system. (Arch Dis Child 1995; 73: F99-F102)
\end{abstract}

Keywords: colostrum, natural killer cells, interleukin-2, peripheral blood mononuclear cells.

Breast milk, which contains carbohydrates, fats, amino acids, minerals and vitamins, is a useful food combination. ${ }^{1}$ It also provides infants with various growth promoting factors, enzymes, and substances such as epidermal growth factor, insulin, and somatomedin. ${ }^{23}$ Passively transferred components such as immunoglobulins, ${ }^{45}$ lactoferrin, ${ }^{56}$ and lysozyme, ${ }^{7}$ all of which may help the baby to fight off infections, have also been detected in breast milk.

Compared with formula feed, breast feeding significantly enhances the $T$ cell mediated response to $\mathrm{BCG}_{\text {vaccine }}{ }^{8}$ and improves $\mathrm{B}$ cell immunity to polyribose phosphate of Haemophilus influenzae $\mathrm{b}$ conjugate vaccine. ${ }^{9}$

Recently, a dual effect of human colostral protein on $\mathrm{T}$ lymphocyte proliferation has been reported - that is, an inhibitory activity at high concentrations of colostrum and an enhanced lymphocyte proliferation at low concentrations. ${ }^{1011}$

The aim of this study was to investigate the effect of colostral milk on the secretion of interleukin-2 (IL-2) and on natural killer (NK) cell activity by normal peripheral blood mononuclear cells (PBMC).

\section{Methods}

Colostral milk was collected from 50 healthy women who delivered spontaneously at Hasharon Hospital, Golda Medical Center. Samples collected on the first three days from onset of lactation were centrifuged $(1500 \times g$, for 15 minutes at room temperature). The supernatant fluid was retained, avoiding pelleted cells and the overlaying fat pellicle. Samples were stored at $-70^{\circ} \mathrm{C}$ until tested.

The concentration of IL-2 in colostrum was tested in 40 samples using the AMI-interleukin-2 RIA kit for the quantitative measurement of human IL-2 (Advanced Magnetic Inc, Cambridge, MA, USA).

Peripheral blood mononuclear cells (PBMC) were isolated from whole blood of healthy volunteers (blood bank donors) by Ficoll Hipaque gradient centrifugation. PBMC were suspended in RPMI-1640 medium containing $1 \%$ penicillin, streptomycin, and nystatin, and supplemented with $10 \%$ fetal calf serum (complete medium).

PBMC $\left(1.5 \times 10^{6}\right)$ suspended in $1 \mathrm{ml}$ complete medium were incubated in the presence of $1 \%$ phytohaemagglutinin (PHA-M; Difco). Colostrum samples were added when the cultures were started at concentrations ranging between 0.5 and $10 \%$. Cultures incubated in the absence of colostrum served as controls. Culture media were collected at 48 hours, the cells were removed by centrifugation, and the supernatant fluids were kept at $-20^{\circ} \mathrm{C}$ until assayed.

IL-2 activity in the supernatant fluids was determined using the IL-2 dependent cell line CTLD, as described before. ${ }^{12}$ Fifty thousand CTLD cells were incubated for 48 hours with the tested samples of supernatant fluids (four serial dilutions, each in triplicate) in 96 flat-bottomed microtitre plates. The results were calculated as units/ml comparable with the IL-2 preparation (supernatant fluid of Concavalin A-stimulated rat splenocytes, arbitrarily regarded as 1000 units).

As colostrum remains in the stomach at low $\mathrm{pH}$ before its resorption, the $\mathrm{pH}$ of 10 colostral milk samples was reduced to 4.0 by adding $\mathrm{HCl}(1 \mathrm{~N}, \sim 4 \mu \mathrm{l}$ to $100 \mu \mathrm{l}$ of colostrum), and after incubating for 60 minutes at $37^{\circ} \mathrm{C}$ the $\mathrm{pH}$ was adjusted back to $7 \cdot 0$ by the addition of $\mathrm{NaOH}(1 \mathrm{~N})$. The influence of treated and non-treated samples of colostrum on PHAinduced IL-2 production by PBMC was investigated.

The possibility that colostrum may directly affect the IL-2 bioassay, and not the production of IL-2, has been tested. Colostral milk was added to supernatant fluids containing IL2 activity at concentrations that might have been present in the supernatant fluids tested for IL-2. After incubation IL-2 activity was determined in the bioassay as described above.

Cytotoxicity was quantified by the standard chromium-51 specific $\left({ }^{51} \mathrm{Cr}\right)$ release assay in 


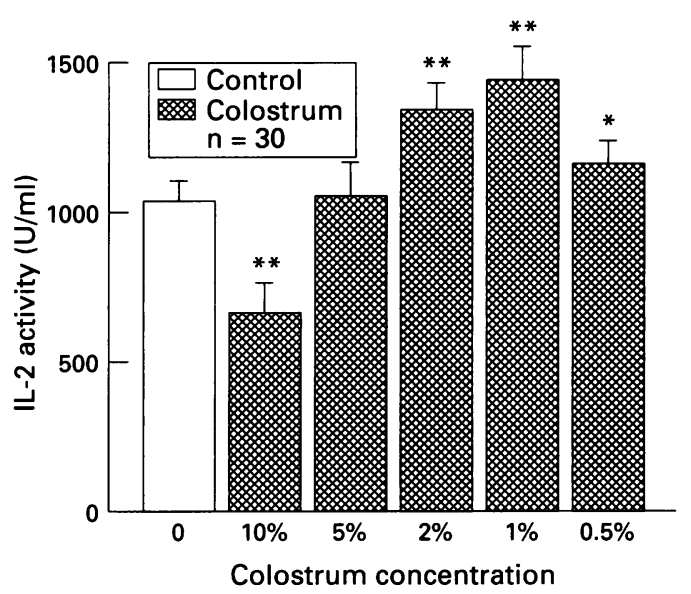

Figure 1 Effect of human colostrum on IL-2 production by human PBMC. Colostrum was added at concentrations as indicated. Bars represent SEM. ${ }^{\star} P<0.05$; $\star \star P<0 \cdot 0025$.

which ${ }^{51} \mathrm{Cr}$-labelled $\mathrm{K}_{562}$ erythroleukaemia cells (targets-T) were incubated with PBMC (effectors-E), ${ }^{13}$ in the absence or presence of the indicated concentrations of colostrum. Final effector to target $(E: T)$ ratios varied from 100:1 to $3: 1$. Cultures were set in 96-well microtitre plates ( $\mathrm{v}$-shaped). The plates were incubated for four hours at $37^{\circ} \mathrm{C}$. At the end of the incubation the plates were centrifuged, 150 $\mu l$ of the supernatant fluids were harvested from each well, and the radioactivity was tested in a $\gamma$-counter (LKB). All reactions were carried out in triplicate and the specific ${ }^{51} \mathrm{Cr}$ release was calculated, as described before. ${ }^{13}$

The effect of colostrum on NK activity was also tested following incubation of aliquots of PBMC $\left(2 \times 10^{6} / \mathrm{ml}\right.$ complete medium $)$ at $37^{\circ} \mathrm{C}$ for 24 and 48 hours respectively, in the absence or presence of the indicated concentrations of colostrum. At the end of the incubation period, the cells were sedimented, resuspended in complete medium, and tested with the cytotoxicity assay.

The effects of human recombinant IL-2 (hrIL-2, Genzyme, Boston, MA, USA) and human leucocyte interferon (IFN, Biological Research Institute, Nes-Ziona, Israel) on NK cell activity were studied on PBMC incubated

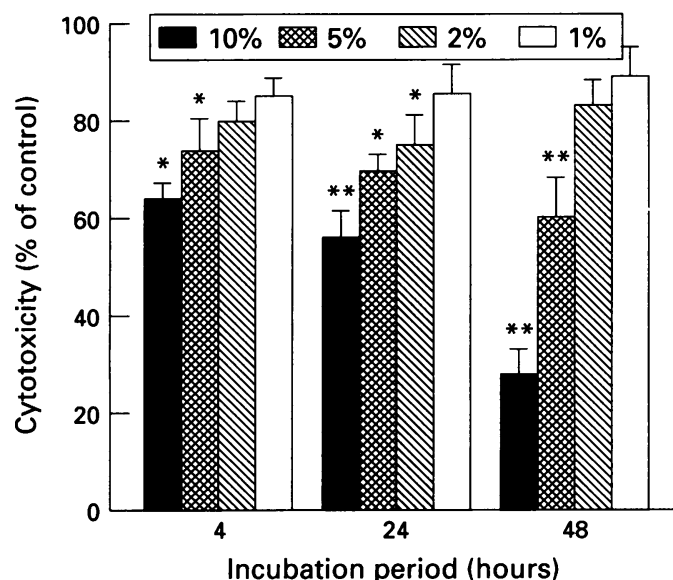

Figure 2 Effect of colostrum on NK cell activity. Colostrum was added to PBMC at the concentrations indicated. NK cytotoxicity was tested at an $E: T$ ratio of 100:1. Bars represent SEM. ${ }^{\star} P<0.05 ;{ }^{\star \star} P<0.0025$. with or without colostrum for 24 hours at $37^{\circ} \mathrm{C}$. HrIL-2 was added at 100 BRMP units $/ \mathrm{ml}$ and IFN at 300 units $/ \mathrm{ml}$, both at the start of the cultures. Following the incubation period ${ }^{51} \mathrm{Cr}$-labelled $\mathrm{K}_{562}$ cells were added at an E:T ratio of 100:1 for an additional four hours and the radioactivity in the supernatant fluids was measured as described above.

Statistical analysis was performed using Student's $t$ test. The results are expressed as mean (SEM).

\section{Results}

The concentration of IL-2 in 37 out of 40 colostral milk samples tested was $10.6(1.3)$ $\mathrm{pg} / \mathrm{ml}$, a value below the sensitivity of the assay kit $(40 \mathrm{pg} / \mathrm{ml})$. However, three samples of colostrum showed high concentrations of IL-2: $646 \mathrm{pg} / \mathrm{ml}, 693 \mathrm{pg} / \mathrm{ml}$, and $1331 \mathrm{pg} / \mathrm{ml}$.

\section{EFFECT OF COLOSTRUM ON IL-2 PRODUCTION}

Colostrum at concentrations as low as $0.5 \%$, $1 \%$, and $2 \%$ showed a significant enhancement of IL-2 production by $14.5(5 \cdot 9) \% ; 41(8 \cdot 7) \%$, and $30 \quad(6.3) \%$, respectively $(P<0.05$; $\mathrm{P}<0.0025$, respectively). At a higher concentration $(10 \%)$, the IL-2 production was significantly inhibited by $35(9.4) \%(P<0.0025)$ (fig 1). These effects on IL-2 production were not altered when the $\mathrm{pH}$ of the colostral milk samples was reduced to $4 \cdot 0$ (data not shown). The possibility that colostral milk may directly affect the IL-2 bioassay, and not the production of IL-2, has been ruled out as the addition of colostrum to supernatant fluids containing IL-2 activity had no effect on that activity (data not shown).

EFFECT OF COLOSTRUM ON NK CELL ACTIVITY The addition of colostrum to PBMC resulted in a dose and time dependent inhibitory effect on the cytotoxic response. At colostrum concentrations of 2,5 , and $10 \%$, the spontaneous killing, tested after four hours of incubation, was significantly decreased by $20(2 \cdot 6) \%$, $25(3 \cdot 5) \%$, and $35(2 \cdot 2) \%$, respectively

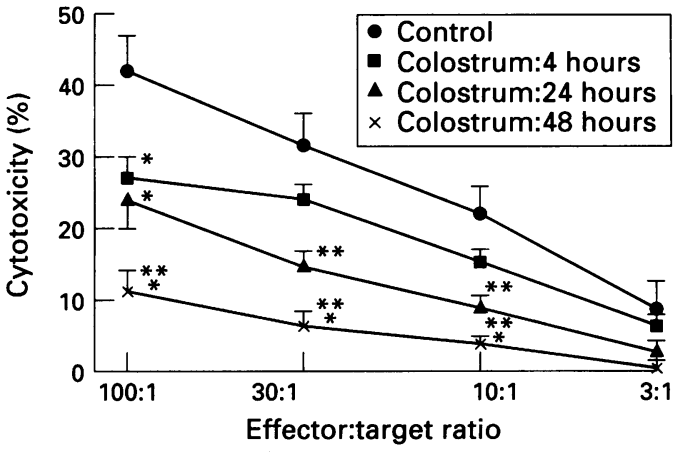

Figure 3 Effect of colostrum on NK cell activity. Colostrum was added to PBMC at $10 \%$ final concentration and NK cytotoxicity was tested at the various periods of incubation time and effector:target ratios as indicated. Each experimental point is the mean of at least seven experiments. Bars represent SEM. ${ }^{\star} P<0 \cdot 05$; ${ }_{\star \star P}<<0 \cdot 0025 ; \star \star \star \star P<0 \cdot 0005$. 


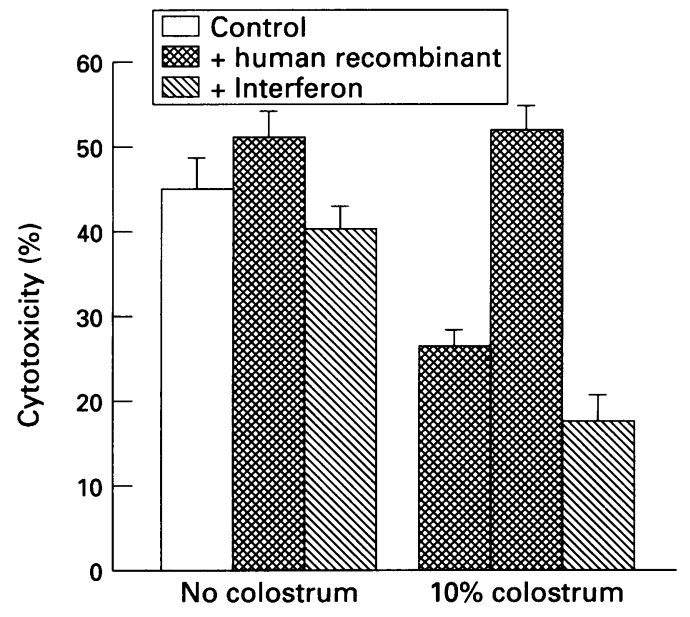

Figure 4 Effect of human recombinant IL-2 (hrIL-2) and human leucocyte interferon (IFN) on NK cell activity. HrIL-2 and IFN were added to PBMC at 100 BRMP units/ml and at 300 unit/ml, respectively. Cultures were incubated for 24 hours before the cells were tested for NK activity at an E:T ratio of 100:1. Bars represent SEM.

$(\mathrm{P}<0.005)$ at an E:T ratio of 100:1 (fig 2). Following 24 and 48 hours of incubation of PBMC with $5 \%$ and $10 \%$ of colostrum, its inhibitory effect on cytotoxicity was more pronounced, showing a reduction of $30(2) \%$ and $44(5.5) \%$ after 24 hours and $40(9) \%$ and 63 $(5 \cdot 3) \%$ after 48 hours, respectively $(P<0.005$; at the same $\mathrm{E}: \mathrm{T}$ ratio). At lower concentrations of colostrum there was a slight, but not significant reduction in NK activity (fig 2 ).

As shown in fig 3 the reduced NK activity caused by colostrum was observed at the four $E: T$ ratios tested in this study - that is, 100:1, $30: 1,10: 1$, and $3: 1$.

Fig 4 shows that the inhibitory effect of colostrum on NK cell activity could be abolished by addition of hrIL-2, whereas human leucocyte interferon did not have any effect.

\section{Discussion}

Our study provides additional evidence that human colostral milk contains substances which exhibit both stimulatory and inhibitory effects on immune function. At concentrations as low as $0.5 \%$, human colostrum enhanced IL-2 production by human PBMC, whereas at a higher concentration (10\%), IL-2 secretion was inhibited. We also observed a time and dose dependent inhibitory effect of colostrum on NK cytotoxicity. This inhibition could be reversed by the addition of hrIL-2.

These results support previous findings which indicated that human colostral milk proteins have both enhancing and inhibitory effects on the proliferative response of human $T$ cells activated by mitogens or alloantigens. ${ }^{10}$ As the proliferation of $\mathrm{T}$ cells is mediated via IL-2, we suggest that the increased and reduced secretion of $\mathrm{IL}-2$ induced by colostrum may provide a possible explanation for the dual effect observed on human cell proliferation. Our results show that the concentration of colostrum needed to achieve stimulation of IL-2 production was 20 times lower than that needed for suppression, a ratio similar to that of colostral milk protein which induced the enhancement and inhibition of cell proliferation. ${ }^{10}$

We have shown that both effects of colostrum on IL-2 production are acid stable, allowing them to resist the action of the low $\mathrm{pH}$ in the stomach.

The inhibitory effect of colostrum on the secretion of IL-2 by PHA stimulated PBMC agrees with the findings of Hooton et al, ${ }^{14}$ who found suppression of IL-2 production by Concanavalin-A activated human PBMC and $T$ lymphocytes induced by colostrum.

Because the newborn's immune response is known to be immature, we suggest that enhanced synthesis of IL-2 induced by colostrum may be of importance for the stimulation of the newborn's immune function.

We have ruled out the possibility that colostrum directly affects the IL-2 bioassay, and not the production of IL-2, as the addition of colostral milk to supernatant fluids containing IL-2 activity had no effect.

The contribution of breast milk to the infant's defence mechanisms has been described before. In addition to a large amount of antibodies (mainly of the secretory IgA class and some $\operatorname{IgM}$ and $\operatorname{IgG}^{15}$ ) and receptor analogues, human milk contains a substantial number of white cells, mainly macrophages $(70 \%)$, lymphocytes (15\%), and granulocytes. ${ }^{1617}$ The colostral macrophages and granulocytes possess a phagocytic capacity whereas lymphocytes exhibit a proliferative response on stimulation with mitogens and antigens. ${ }^{1617}$ Furthermore, supernatant fluids from cultivated colostral cells, on stimulation, can produce IL-1 ${ }^{1819}$ (Sodar O. Abstract presented at VI International Congress of Immunology, Toronto, Canada, 1986), IL-2, ${ }^{18}$ and chemotactic factor activity. ${ }^{20}$ According to our results, IL-2 concentrations in colostral milk were very low or even undetectable, suggesting that, although colostral cells are able to produce cytokines on stimulation in vitro, comparable stimulation for IL-2 production does not exist in vivo. Other cytokines such as epidermal growth factor (EGF), ${ }^{21}$ IL- $1 \beta,{ }^{22}$ tumour necrosis factor- $\alpha$ (TNF- $\alpha)^{23}$ and transforming growth factor (TGF) ${ }^{24}$ have also been found in colostrum. The latter has been shown to have an inhibitory effect on IL-2 production by EL-4-NOB-1 murine thymoma cells ${ }^{25}$ and thus may also be responsible for the suppression of IL-2 secretion reported here. In addition, we have not excluded the possibility that some components of human milk may alter detection of IL-2, as has been described for TNF- $\alpha .^{23}$

Some of the humoral factors that suppress maternal NK activity in pregnancy ${ }^{13}$ may be present in colostrum and are most probably responsible for the lower NK activity reported in the newborns. ${ }^{26-28}$ In addition, the high concentrations of immunoglobulins found in colostrum may also suppress NK activity, as has already been documented. ${ }^{29}$ According to our findings, the inhibitory effect of colostrum on NK activity can be completely reversed by the addition of hrIL-2. Thus, the stimulation of IL-2 production induced by low concentrations 
of colostrum which we observed may compensate for its inhibitory effect on NK activity.

1 Lonnerdal B. Biochemistry and physiological function of human milk proteins. Am $\mathcal{F}$ Nutr 1985; 42: 1299-317.

2 Carpenter G. Epidermal growth factor is a major growth promoting agent in human milk. Science 1980; 210: 198-9.

3 Baxter RC, Zaltsman Z, Turtle JR. Immunoreactive somatomedin-C/insulin-like growth factor I and its binding protein in human milk. $\mathcal{F}$ Clin Endocrinol Metab 1984, 58: $955-9$.

4 Goldman AS, Garza C, Nichols BL, Goldblum RM. Immunologic factors in human milk during the first year of lactation. $\mathcal{F}$ Pediatr 1982; 100: 563-7.

5 Spik G, Cheron A, Montreuil J, Dolby JM. Bacteriostasis of a milk sensitive strain of Escherichia coli by immunoglobulins and iron-binding proteins in association. Immunology 1978; 35: 663-71.

6 Arnold RR, Cole MF, McGhee JR. A bactericidal effect for human milk lactoferrin. Science 1977; 197: 263-5.

7 Barry RM, Chandan RC, Shahani KM. Isolation and characterization of human milk lysozyme. Arch Biochem Biophys 1960; 103: 59-61.

8 Pabst HF, Godel J, Grace M, et al. Effect of breast-feeding on immune response to BCG vaccination. Lancet 1989; on imm $295-7$.

9 Pabst HF, Spady DW. Effect of breast-feeding on antibody response to conjugate vaccine. Lancet $1990 ; 336: 269-70$.

10 Mincheva L, Nilsson M, Hammarstrom L, et al. Human milk contains proteins that stimulate and suppress $\mathrm{T}$ lymphocyte proliferation. Clin Exp Immunol 1990; 79: 463-9.

11 Hanson LA, Ahlstedt S, Andersson B, et al. Protective factors in milk and development of the immune system. Pediatrics 1985; 75 (suppl): 172-6.

12 Serrate SA, Schuloff RS, Leonidaridis L, et al. Modulation of natural killer cell activity, lymphokine production and IL 2 receptor expression by thymic hormone. $f$ Immunol 1987; 139: 2383-8.

13 Baley JE, Schacter BZ. Mechanisms of diminished natural killer cell activity in pregnant women. F Immunol 1985; 134: 3042-8.

14 Hooton JWL, Pabst HF, Spady DW, Paetkau V. Human colostrum contain an activity that inhibits the production of IL-2. Clin Exp Immunol 1991; 86: 520-4.
15 Hanson LA. The mammary gland as an immunological organ. Immunol Today 1982; 3: 168-72.

16 Cargo SS, Mestecky J. Human colostral cells: II. Response to mitogens. Cell Immunol 1984; 86: 222-5.

17 Smith JW, Schultz RD. Mitogen- and antigen-responsive milk lymphocytes. Cell Immunol 1977; 29: 165-73.

18 Nikolova E, Staykova M, Raicheva D, et al. Interleukin production by human colostral cells after in vitro mitogen stimulation. Am $\mathcal{F}$ Reprod Immunol 1990; 23: 104-6.

19 Subiza JL, Rodriguez C, Figueredo A, Mateos P, Alvarez R, De la Concha EG. Impaired production and lack of secretion of interleukin-1 by human breast milk macrophages. tion of interleukin-1 by human bre

20 Keller MA, Kidd RM, Bryson IJ, et al. Lymphokine production by human milk lymphocytes. Infect and Immun 1981, 32: 632-6.

21 Iacopetta BJ, Horisberger M, Sunahara GI. Epidermal growth factor in human and bovine milk. Acta Pediat 1992; 81: 287-91.

22 Munoz C, Endres S, van der Meer J, Shlesinger L, Arevalo $M$, Dinarello C. Interleukin-1 beta in human colostrum. Res Immunol 1990; 141: 505-13.

23 Rudloff HE, Schmalstieg FC Jr, Mushtaha AA, Liu SK, Goldman AS. Tumor necrosis factor-alpha in human milk. Pediatr Res 1992; 31: 29-33.

24 Espervik T, Waage A, Faxvaag A, Shalaby MR. Regulation of interleukin-2 and interleukin-6 production from $T$ of interleukin-2 and interleukin-6 production from Tcells: involvement of interleukin-1 beta and transform

25 growth factor beta. Cell Immunol 1990; 126: 47-56. activity in human colostrum. Gann 1984; 75: 109-12.

26 McDonald T, Sneed J, Valenski WR, et al. Natural killer cell acDonald T, Sneed J, Valenski WR, et al. Natural killer cell activity in very

27 Sanco L, de la Hera A, Casas J, Vaquer S, Martinez-A C Alvarez-Mon M. Two different maturational stages of natural killer lymphocytes in human newborn infants. $\mathcal{F}$ Pediatr 1991; 119: 446-54.

28 Engelhard D, Waner LJ, Kapoor N, Good AR. Effect of intravenous immune globulin on natural killer cell activity: possible association with autoimmune neutropenia and idiopathic thrombocytopenia. $f$ Pediatr 1986; 108: 77-81.

29 Chirico G, Maccario R, Montagna D, Chiara A, Gasparon A, Rondini G. Natural killer cell activity in preterm A, Rondini G. Natural killer cell activity in preterm tration. $\mathcal{f}$ Pediatr 1990; 117: 465-6. 